\title{
Systems Dynamics and Empirical Studies of Innovation in the Automotive Industry
}

\author{
Bryan MOSER ${ }^{\mathrm{a}, \mathrm{b}, 1}$ Amardeep SINGH ${ }^{\mathrm{a}}$, and Yuru ZHANG ${ }^{\mathrm{a}}$ \\ ${ }^{a}$ System Design and Management, Massachusetts Institute of Technology, MA USA \\ ${ }^{\mathrm{b}}$ Graduate School of Frontier Sciences, University of Tokyo, Japan
}

\begin{abstract}
After a brief period of entrepreneurship and competition, the automotive industry settled into a tiered structure aligned with the assembly decomposition of the vehicle. In recent years, changes to automobiles, mobility, and energy are rapidly transforming the industry with potential to disrupt the classic roles of OEMs and Tier-1 suppliers. Several new large actors from outside the industry are now competing. This research leverages two methods to investigate how innovation diffusion impacts the position of Tier-1 suppliers. A system dynamic modeling approach and an empirical study were conducted for subsystems in this industry since 1990. The research progress and limitations from these methods separately, then in combination, are discussed with insights for further work and transdisciplinary studies in engineering.
\end{abstract}

Keywords. Automotive innovation, Tier-1 supplier, transdisciplinary studies of engineering

\section{Introduction}

This paper shares two studies of different methods towards a common question: Can innovation by Tier 1 automotive suppliers significantly change their position and performance given the traditional layered industry? An initial study leveraged existing theory to build a system dynamics model of innovation dynamics in the automotive industry. A second study applied an empirical approach, surveying industry experts and collecting product data. The interplay across the two methods helped the researchers to expand insights and refactor several times, in a back and forth exchange that strengthened both results.

Transdisciplinarity, a term originally coined in the 1970s as a concept in science research with an emphasis in sustainability, has been more recently considered in engineering of complex systems. [1]-[3] Engineering is faced with great challenges requiring innovation beyond the integration of existing disciplinary capabilities. [4] For the automotive industry, approaches to product development - suitable for newer complex, connected systems - require adaptation across technical and organizational decisions. For new product development, what uncertainty and change can be handled feasibly and desirably within limits of capability, resources, and time? How will new technologies compare to what other can and will do? Given a choice to innovate in a certain area, will the investment pay off? Thus, these engineering choices must leverage multiple disciplines within and outside engineering in combination.

\footnotetext{
${ }^{1}$ Corresponding Author, Mail: bry@mit.edu
} 
The early decades of the automotive industry were a period of diverse players and entrepreneurship, soon displaced by an enduring structure of dominant Original Equipment Manufacturers (OEMs) served by a multi-tiered supplier hierarchy.[5] The OEM sits at a top (level zero) layer and suppliers are arranged in tiers aligned by product decomposition. A Tier-1 (level one) company supplies subsystems to the OEM, Tier 2 companies supply Tier-1, and so on. In this classic model, the supplier is "owned' by the OEM, either as vertically integrated division or captured by reliance for market insights and revenues. In this environment the Tier-1 supplier may find it difficult to divert attention from the command of the OEM nor otherwise to compete. In recent decades, challenges to this dominant structure have come and gone, or been absorbed.

\section{Innovation and the Auto Industry}

Competition from Japanese makers in the 1980s (enabled by loosely coupled vertical integration and lean capabilities) was followed by offshoring and modularity trends of the late 1990s. Indeed, some suppliers have been able to overcome previous limitations, becoming suppliers across multiple OEMs. Still, the predominant industry structure has not changed. The OEMs retain their dominant positions and the role of the Tier 1 suppliers has remained relatively unchanged. Jacobides et.al. studied the movements towards outsourcing and modularity $(\mathrm{O}+\mathrm{M})$ in the $1990 \mathrm{~s}$, which had the possibility to change the OEM role and industry structure [5]. In their study they argue that even as the Tier-1 suppliers ("mega suppliers") increased their capabilities, the OEM continued to invest even more in R\&D, to "know more than they make" [6]. They concluded that these initiatives, though widespread, were mostly reversed as OEMs recognized their role as integrator and the need to control suppliers. The authors go on to extrapolate recent potentially disruptive technologies such as electrification, batteries, and autonomy, asserting that the suppliers will not change the dominant industry architecture of the last century. They also argue that new entrants, such as Tesla, adhere to the classic pattern. The research objective of this paper was triggered by this assertion.

\subsection{Open Innovation and Supplier Position}

Through open innovation, ideas originate from (1) inside the company's research process, and (2) outside the company and transferred inside. Some ideas also move out of the company, either early on, after opportunity identification and product planning, or later during the product development phases [7]. While many ideas in early phase do not see the light of day, the process of open innovation enables diversity of ideas generated both internally and external to the company. Lazzarotti et al.[8] studied European suppliers along with an OEM, noting that rarely do intellectual property (IP) and ideas flow to competition nor players in other industries. A mix of openness to collaborate (inbound innovation) is observed between the OEM, its suppliers, and others (e.g. competitors, cross-industry players, universities, customers, and research centers). A supplier's view of open innovation is explored by Brown et al.[9], emphasizing need for organizational and cultural shifts. In addition to collecting ideas through internal and external channels, Delphi, though an internal service, involved suppliers in product innovation, technical issues, inter divisional co-operation, and business case validation.

Chesborough [10] discusses the latent economic value of a technology or invention until it is commercialized, referring to a business model as "the architecture of revenue." 
He highlights that "a mediocre technology pursued with a great business model may be more valuable than a great technology in a mediocre business model." New business models related to car sharing ecosystems, insurance, and mobility industries are expected in the coming years [11]. Tesla is an example of both technology and business models breaking conventions of the automotive industry. [12]

Parker and Van Alstyne imagine a firm as manager of a micro-economy, shaping an ecosystem with an emphasis on how innovation is open, closed and for how long. [13] Given specialized supplier capability, how long should intellectual property (IP) rights be protected in their micro-economy? Amongst trade-offs, they recognize the need for the supplier to retain rights, maintain price and gain advantage from their invention. At the same time, they describe potential benefit of the commons -- knowledge moving beyond the particular inventor and having an impact across suppliers.

\section{A Systems Dynamics Study}

This research began by looking at the auto industry as a system of stakeholders exhibiting value flow amongst them. Focused on Tier-1 and the OEM, a hypothesis explored competition between the Tier-1 supplier and the OEM and its effect on the dilution of innovation. A tension exists internal to the OEM, between internal vs. external innovation. While internal innovation may be time consuming, costly, and maintains control over the market, outsourced innovation is less expensive, can be expedited through competition between suppliers, yet might result in little to no innovation lead for the OEM.

An initial model built to test the original research hypothesis is shown in Figure 1. Starting in the upper left with the IP Driven (R1) loop, all else being equal, research generates patents after some delay. Increasing research will lead to more patents, more patents lead to greater product innovation which then increases innovation lead. Innovation lead is defined here as the advantage gained by converting internally developed technology into products from which the OEM alone benefits.

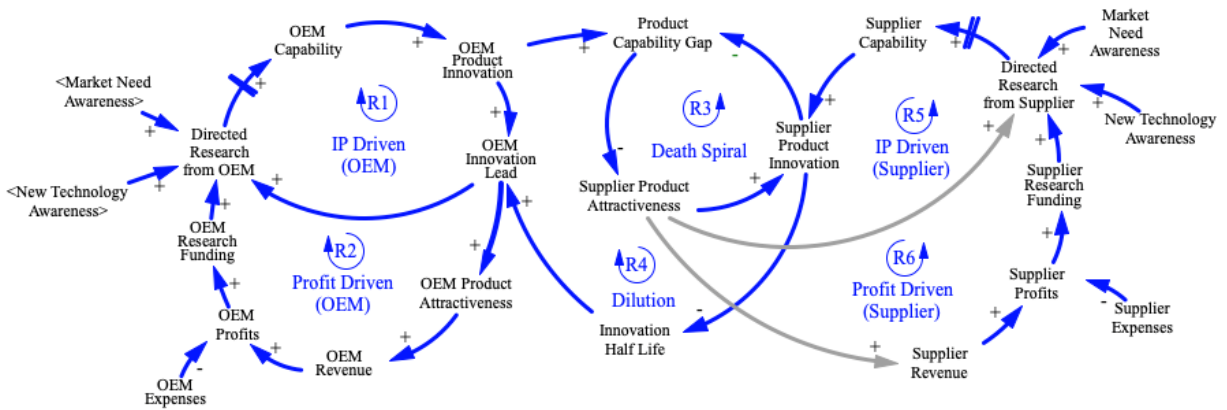

Figure 1: Causal loop diagram depicting OEM vs. Tier-1 supplier innovation model.

A second OEM causal loop is shown on the bottom left: Profit Driven (R2). Characterized by product attractiveness, revenue, profits, and research funding, the loop shows the profit incentive for funding of research. As Innovation Lead increases, Product Attractiveness also increases if the OEM uniquely offers the innovation in the market. Higher attractiveness leads to greater Sales and more Revenue. For given OEM expenses, higher revenue increases profits, which further increases research funding. Higher funding leads to an increase in projects that address market needs. 
Shown on the right side of Figure 1, innovation by the supplier is modeled with four reinforcing loops. The Dilution loop (R4) captures a product system's useful commercial life. As Supplier Product Innovation increases, the Innovation Half Life, the time it takes for a product feature to reduce to half its original value, decreases. In other words, Innovation Half Life captures a premium product devolving into a base product -- a standard on cars from all manufacturers. OEMs attempt to increase half-life by maximizing lead over competition as long as possible. Meanwhile, the supplier's objective is to sell its innovation to many OEMs, displacing previous innovations and reducing half-life. Decrease in Innovation Half Life decreases Innovation Lead for the OEM. A lower lead drives decrease in Research Studies, and thus fewer patents. Fewer patents will result in lower product innovation, which in turn leads to lower Product Capability Gap. A higher capability gap is better for the OEM. Back in loop R4, as the gap decreases, Supplier Product Attractiveness increases, and higher attractiveness of supplier product leads to greater Supplier Product Innovation.

A second reinforcing loop, the Death Spiral (R3), drives loss of supplier product innovation. As Product Capability Gap increases, Supplier Product Attractiveness reduces, decreasing Supplier Product Innovation in that particular product segment. Lower Supplier Product Innovation in turn increases Product Capability Gap, resulting in loss of value for the supplier. Similar to the OEM, a supplier is influenced by an IP loop (R5). In R5, high Supplier Product Attractiveness drives increase of Supplier Research for the given funding, market needs and technology awareness. More effort by the supplier will increase patents, after some delay. High product innovation at the supplier side will result in smaller Product Capability Gap, which then leads to greater Supplier Product Attractiveness.

A Profit Driven loop (R6) captures the financial side of innovation on the supplier side. As Supplier Product Innovation increases, Supplier Sales increase. Higher sales then result in greater revenue for the suppliers. For given expenses, higher revenue results in greater supplier profits, thus increasing funding of new capability in the relevant segment. Greater research effort after some delay leads to more patents and Supplier Product Innovation. This increase in innovation then decreases the Product Capability Gap. An exogenous variable, Market Need Awareness, captures the supplier's insight into the market from working with multiple OEMs, suppliers, and technology trends. New Technology Awareness captures the level of awareness of technology not native to the automotive industry. These variables also influence OEMs research efforts.

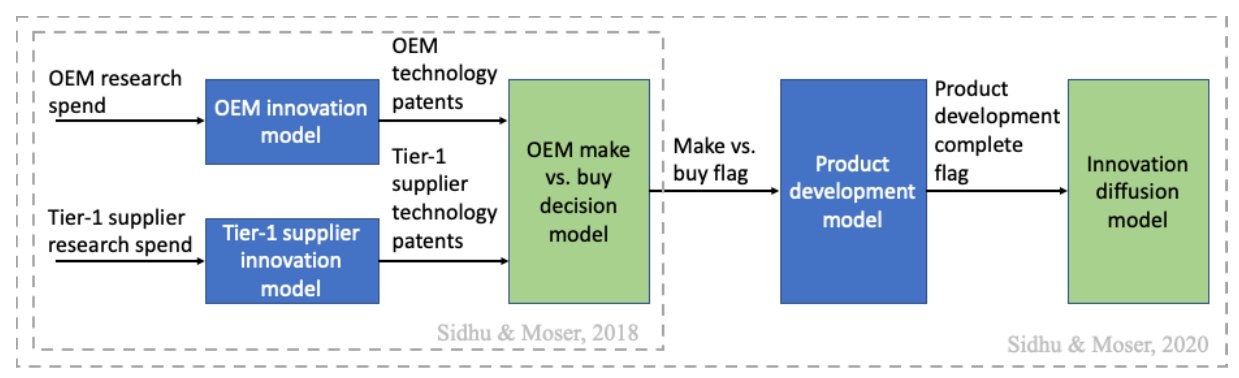

Empirical study focus, 2021

Figure 2: Overview of model-based study into automotive innovation adoption and diffusion.

Figure 2 shows the two stages of the model-based study. The innermost dashed box on the left represents the initially proposed causal loop model. Limitations of the initial model triggered an expansion and the need for the empirical study. Even early on, as the 
empirical study was being framed, the exercise revealed insights in two areas: the aftermath of a "buy" decision by the OEM for one product feature, and the diffusion of this product feature into car models offered by major North American (NA) manufacturers. The impact of the empirical study on the expanded model is represented by the green boxes in Figure 2, and discussed further in section 4 .

\section{An Empirical Study}

In response to the first stage of the model-based approach, a separate empirical study was started focusing on two innovation dynamics: the competition between OEMs and Tier-1 suppliers (Red Queen Dynamics), and diffusion of technical innovation. North American automotive supplier relationships are tense, with aggressive projections, low profit margins, various regulatory standards, and dependence on the OEM. Tier-1 suppliers invest in various capabilities; talent acquisition, IP development and protection, innovative products, and marketing. Tier 1 suppliers seek to improve position and achieve an increased profit margin, less dependence on a single OEM, and products offerings across multiple OEMs.

The empirical approach selects a motor vehicle subsystem and draws insights from the "who supplies whom" interactions and their relationship to development of capability. The authors began with functional decomposition of a typical light-weight vehicle and identified 17 subsystems with innovation cycles over the last three decades (1990 to 2019). As is shown in Figure 3, the subsystems include powertrain, chassis, interior \& comfort, infotainment \& telematics, and advanced driver assistance systems.

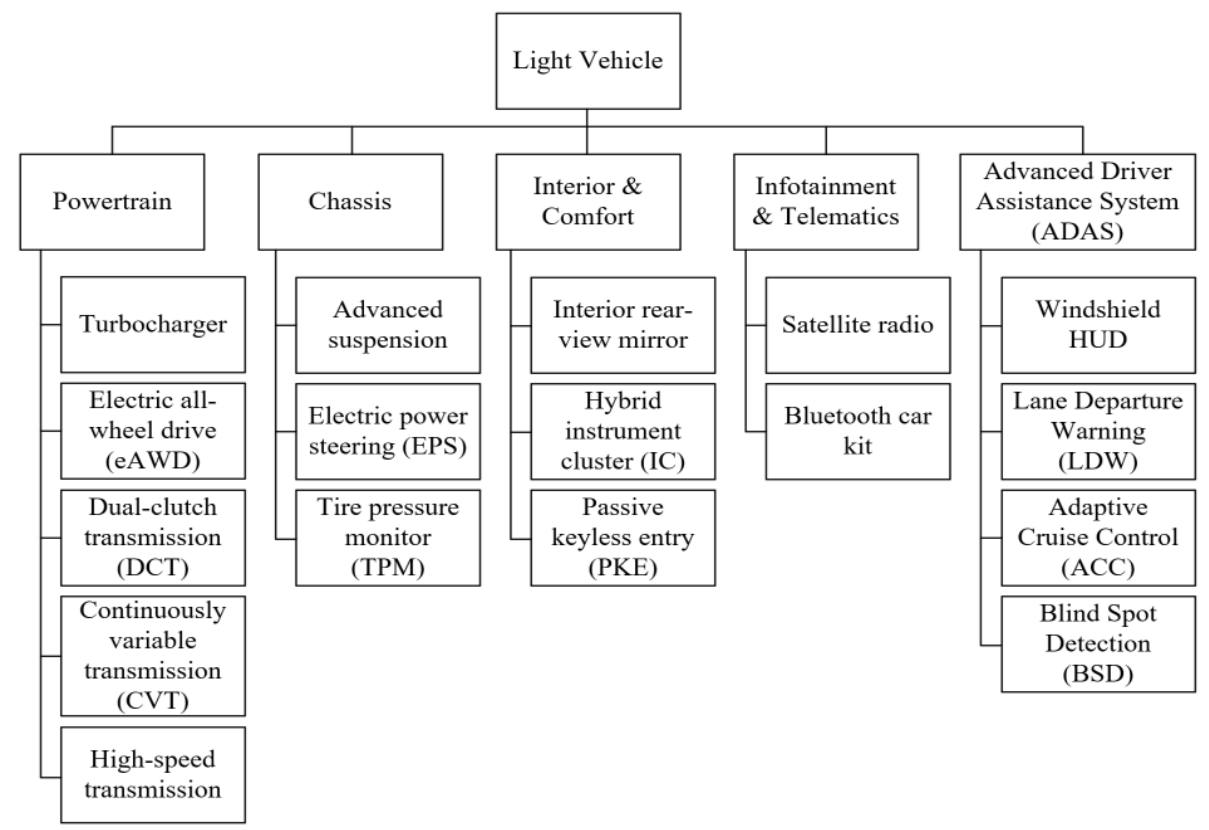

Figure 3: Light Vehicle product system decomposition used for evaluation and selection of product subsystems for the empirical study. 
To prioritize and down-select candidate subsystems, a survey was conducted with mid-career product development professionals in the automotive industry, followed by several interviews. The survey evaluated the 17 Tier-1 subsystems based on four factors: pace of market adoption, breadth of technology diffusion, level of technical defensibility, and value to the total system performance and degree of potential achieved. The survey identified the passive keyless entry (PKE) as a top candidate for this study. PKE offers convenience of hands-free entry to a vehicle and ignition start, with the key fob remaining in the customer's pocket. The technology was first developed by Siemens VDO and introduced to the market by Mercedes-Benz before 2000 and reached an installation rate of around $20 \%$ in 2018. Based on light vehicles in the North American market, the study's period is aligned with the technology's first entry to market until a full innovation cycle is suggested by market diffusion. The study was designed for and intended for multiple Tier-1 subsystems with PKE as an initial subsystem. (Additional subsystem evaluations are in process). The automotive models of two major North American OEMs - General Motors (GM) and Ford Motor Company, are included, representing $30-40 \%$ of the US light-vehicle market, with 99 current and discontinued models from brands including Ford, Lincoln and Mercury from Ford, and Cadillac, Buick, Chevrolet, and GMC from GM.

Data of OEMs and Tier-1 suppliers were collected from publicly available data sources, including financial statements, vehicle owner's manuals, vehicle sales databases, product catalogs from various parts vendors, and the FCC database[14]. Data starts from model year 2004, when GM first introduced PKE in the Cadillac XLR, to 2020, the most recent complete model year. The number of models and sales data for a few light-truck models (i.e. F-series from Ford and Silverado from GM) are aggregated to align with OEMs sales release. Figure 4 and Figure 5 show PKE availability and estimated vehicle shipments between 2004 and 2020 .

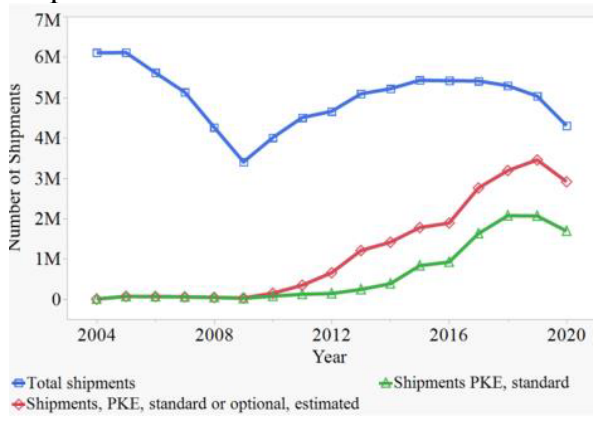

Figure 4: PKE Adoption by Model: Number of N.A. models (Ford and GM) compared to models with optional or standard PKE

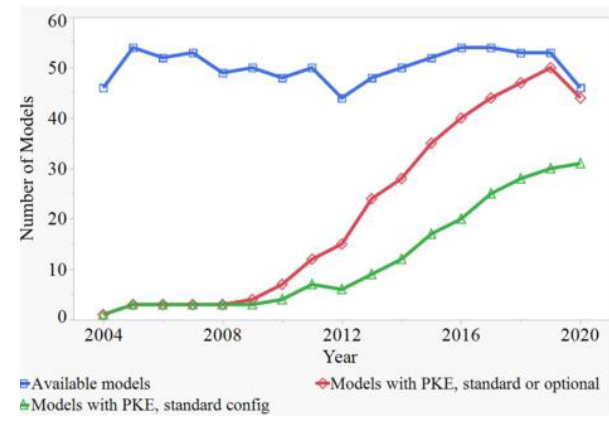

Figure 5: PKE Adoption by Vehicles Shipped: Shipments of vehicles (US) Ford and GM, compared to vehicles with PKE.

Diffusion of PKE follows the adoption s-curve: an initial period of slow growth between 2004-2009, followed by a fast adoption period between 2010-2018, and culminated with a plateau around 2020-2021. By the end of model year 2020,95\% of models manufactured by GM and Ford offered PKE either as standard or optional configuration, with an estimated $67 \%$ new vehicles equipped with PKE.

Figure 6 shows a comparison between Ford and GM. Ford introduced PKE to its customers in 2009, 4 years later than GM. However, the diffusion of PKE in Ford models is faster than GM. For example, $90 \%$ of models from Ford offered PKE at least as an option in model year 2015 while GM offered only 55\%. Figure 7 show a Sankey chart 
to illustrate the evolution of the number of OEM vehicle models supplied by Tier-1 suppliers in model years between 2004 to 2020. Siemens VDO (later acquired by Continental AG in 2007) was the first developer of PKE subsystems and therefore benefited as first mover. Siemens VDO/Continental supplied most vehicle models with PKE technology in the early adoption stage between 2004-2010, with competition from Hella and Strattec. A new competitor - Denso, emerged in GM's PKE supply chain in 2014 and became the dominant supplier of GM's PKE subsystem within 3 years. By the end of model year 2019, Continental was no longer on GM's PKE supplier list but remained as the sole supplier of PKE for Ford. By this point, Denso supplied 30 of 32 GM models offering PKE. Other Tier-1 suppliers remaining include Hella, which supplied PKE for GM's Corvette, a performance convertible, and Strattec supplying GM's Impala, a full-size car model discontinued in the model year 2020.

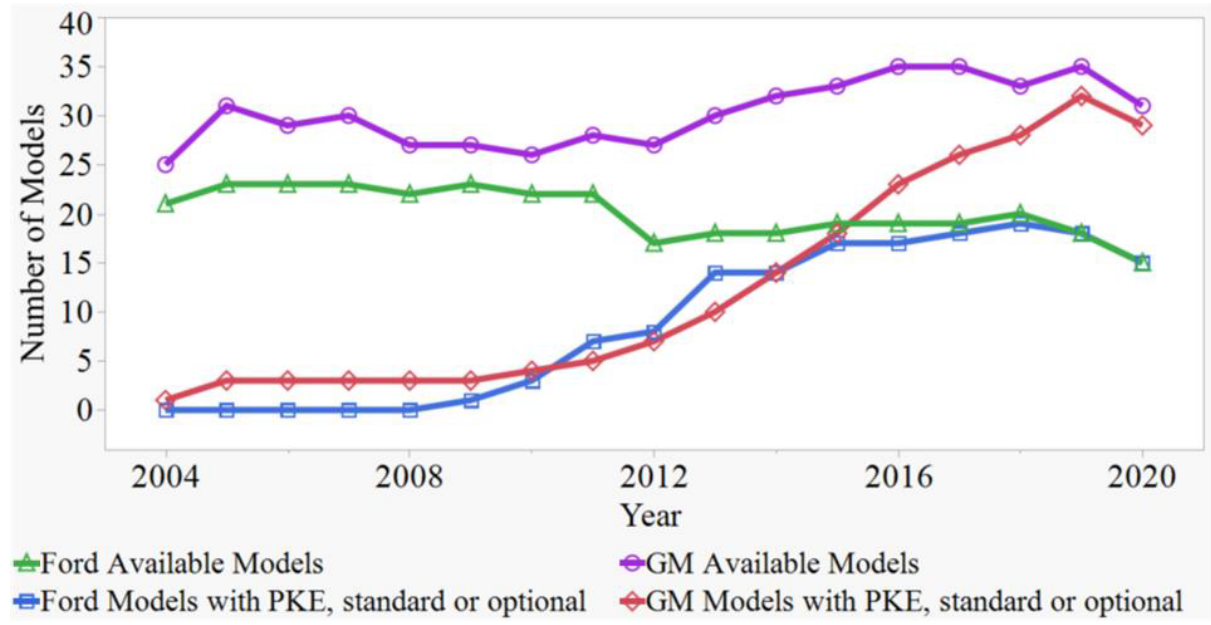

Figure 6: Adoption of PKE across Ford and GM, 2004 - 2020.

What is behind Denso's rise in GM's PKE supply chain? Denso has a good relationship with GM, awarded GM's top supplier awards for quality for many years, thus it is not surprising to see Denso emerge as a GM PKE supplier. Though Siemens VDO was the inventor of PKE, Denso was also a forerunner in keyless access systems. The company introduced RF technology to RKE systems as early as 1984 and owned similar market share of PKE systems as compared with Siemens VDO in 2006. 28\% of Denso is owned by Toyota, supplying RKE and PKE systems to Lexus before 2006.

Why does Ford keep staying with Continental? Ford has collaborated with Siemens VDO/ Continental throughout the PKE diffusion curve. In a 2006 analyst's report, Ford did not consider convenience from PKE as a core user experience, outsourcing PKE to a Tier-1 supplier. This initial decision may have shaped Ford's product vision and supply chain management, leading to Continental as the only supplier to Ford's PKE systems.

\section{Discussion}

The two studies, still underway, seek to determine if and how an outsized investment in innovation by a Tier 1 supplier might change the position of suppliers compared to the historical pattern. In contrast to a typical model-building and validation exercise, in 
which the empirical study follows simply as calibration and validation, the two studies were framed, refined, and validated to some degree by the other. At the time of this conference paper draft, only a single subsystem has been evaluated. Market position outcomes data are still needed. However, the researchers summarize here the ongoing interplay between the two studies.

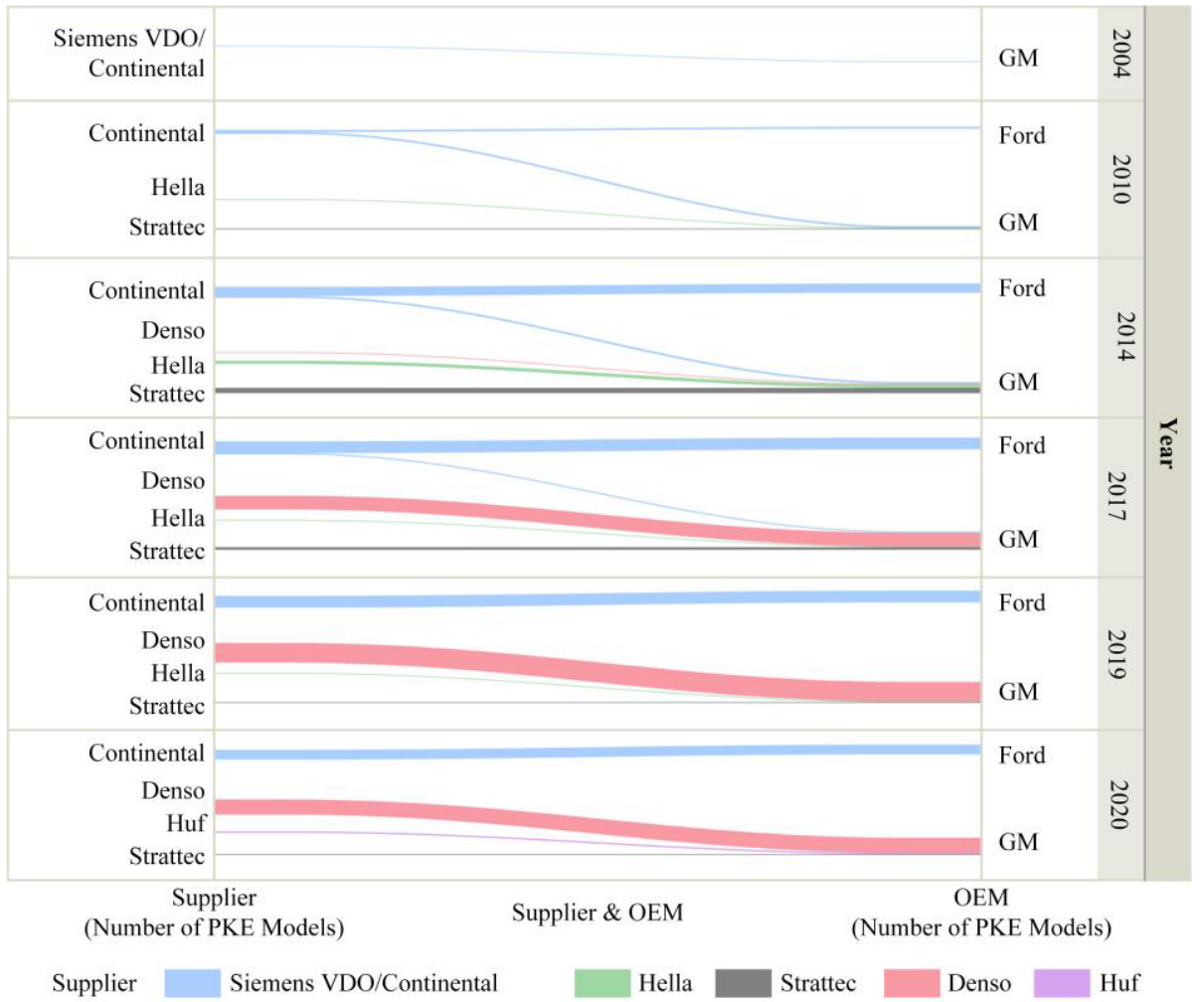

Figure 7: Adoption and Diffusion from Tier 1 Supplier to OEM for PKE, 2004 -2020

Dynamics missing in the initial SD model were stimulated by the empirical study, such as a weak reinforcing loop due to aftermarket products. The empirical study showed suppliers offering PKE kits to retrofit old models. An updated model in response to this insight includes shipments from aftermarket boosting the "market need awareness" and "new technology awareness" as input to supplier loops. The empirical study also revealed multiple OEM relationships for Tier-1 suppliers. In contrast, an early SD model was overly focused on one-to-one relationships. In response, (see Figure 2), the evolution of the SD model emphasized broader one to many diffusions. Further, make-buy decisions were modeled in a static way, and the empirical study exposed these decisions more clearly. In the case of PKE, the rise of Denso to dominate shows a Tier-1 player dynamically capturing the market.

The original SD model also assumed a stage-wise new product development with uniform "time equals zero" signaling the start of new capability investment. However, in the Siemens PKE case, product development had already happened and early diffusion was a leverage rather than development of capability. Likewise, the SD model assumes a product development process consistent across actors in the market. However, process capability, including accelerated model-based, start-up, agile, and platform approaches 
might explain a different dynamic. In the empirical study, interpretation of the duration from early prototypes to market entry could be explained better with this context.

In the second model, even with added system dynamics (SD) language to capture make vs. buy, technology integration, and innovation diffusion, several limitations remain. While data is available for total research spend and patents filed, these lack sufficient granularity to calibrate the SD model. The model would benefit from data on technology specific research spend, patents filed, product development, and product diffusion. Research funding to patent filing latency likely differ across OEMs and suppliers. These delays will not be clear unless technology specific data is available. Patent value and fit rather than assuming all patents have the same value. Rework cycle, project controls, and ripple and knock-on effects on product development could be considered to improve robustness of the model. Advertising effectiveness, contact rate, and adoption fraction will not be the same for all innovation diffusion. However, using the available diffusion data, these parameters can be identified.

The empirical study brought tangibility and real-world time scale, as seen through the innovation, introduction, and diffusion of a new technology across a real set of car models and multiple OEMs. Early on for the empirical study, the researchers endeavored to reduce influence of assumptions and insights of the system dynamic model, and instead considered how to capture and synthesize the actions, introduction, and diffusion unbiased by prior assumptions. In the framing of the empirical study, the structured decomposition of the product system and selection of target subsystems revealed certain types of subsystems that don't fit neatly into the framing of the problem in the SD model. In particular, subsystem products that are demanded and visibly directly by end users, for example software and communications platforms such as SiriusXM, Apple CarPlay, and Android Auto. The selection of subsystem in the empirical model triggered us to include TRL into the empirical study, which in turn is promising to consider in the SD model, as certain subsystem may not be yet in a state of sufficient maturity for viable adoption and diffusion. This limitation was seen again in powertrain subsystem examples, with certain hybrid or electric platforms early in their innovation cycle.

Several market entries are explained by capability acquisition, a phenomenon not clear in the SD model. The empirical study showed patterns of entry and diffusion at two different OEMs, GM and Ford, affirming a consistency across all models and a few exceptions due to acquisition. In another case, some Tier-1 suppliers act in partnership and strategic alliances, thus make-buy may also exist across the Tier 1 suppliers.

This back and forth has increased the research team's findings of limitation and possible extensions, otherwise easily skipped. A model paints a limited picture (all models as wrong, some are useful). The empirical study not only drove expansion and refinement of the model, but to also have more respect for its limits, inspiring the researchers to develop new, separate models.

\section{References}

[1] S. L. Ahire and T. Ravichandran, An innovation diffusion model of TQM implementation, IEEE transactions on engineering management, 2001, Vol. 48, No. 4, pp. 445-464.

[2] M. Atalay, N. Anafarta, and F. Sarvan, The relationship between innovation and firm performance: An empirical evidence from Turkish automotive supplier industry, Procedia social and behavioral sciences, 2013, vol. 75, pp. 226-235.

[3] M. Bensaou, Interorganizational cooperation: the role of information technology an empirical comparison of US and Japanese supplier relations, Information Systems Research, 1997, Vol. 8, No. 2, pp. 107-124. 
[4] A. Brem and G. Schuster, Open Innovation and the Integration of Suppliers-Literature Review and Discussion on Supplier Innovation, in A. Brem and J. Tidd (eds.) Perspectives on supplier innovation: Theories, concepts and empirical insights on open innovation and the integration of suppliers, Imperial College Press, London, 2012, Vol. 18, pp. 67-94.

[5] S. C. Ellis, J. W. Henke Jr, and T. J. Kull, The effect of buyer behaviors on preferred customer status and access to supplier technological innovation: An empirical study of supplier perceptions, Industrial marketing management, 2012, Vol. 41, No. 8, pp. 1259-1269.

[6] B. H. Hall and B. Khan, Adoption of new technology, National bureau of economic research, 2003.

[7] A. Hanelt, S. Firk, B. Hildebrandt, and L. M. Kolbe, Digital M\&A, digital innovation, and firm performance: an empirical investigation, European Journal of Information Systems, 2020, pp. 1-24.

[8] J. W. Henke Jr and C. Zhang, Increasing supplier-driven innovation, IT Management Select, 2010, Vol. 16, pp. 41-46.

[9] R. "Bryan" Jean, D. Kim, and R. R. Sinkovics, Drivers and performance outcomes of supplier innovation generation in customer-supplier relationships: The role of power-dependence, Decision Sciences, 2012, Vol. 43, No. 6, pp. 1003-1038.

[10] R. "Bryan" Jean, R. R. Sinkovics, and T. P. Hiebaum, The Effects of Supplier Involvement and Knowledge Protection on Product Innovation in Customer-Supplier Relationships: A Study of Global Automotive Suppliers in China, Journal of Product Innovation Management, 2014, Vol. 31, No. 1, pp. 98-113.

[11] T.E. Johnsen, Supplier involvement in new product development and innovation: Taking stock and looking to the future, Journal of Purchasing and Supply Management, 2009, Vol. 15, No. 3, pp. 187197.

[12] J.-P. Kramer, E. Marinelli, S. Iammarino, and J. R. Diez, Intangible assets as drivers of innovation: Empirical evidence on multinational enterprises in German and UK regional systems of innovation, Technovation, 2011, Vol. 31, No. 9, pp. 447-458.

[13] J. P. MacDuffie and S. Helper, Creating lean suppliers: diffusing lean production through the supply chain, California management review, 1997, Vol. 39, No. 4, pp. 118-151.

[14] J. A. Machuca, C. H. O. Jiménez, and P. Garrido-Vega, Do technology and manufacturing strategy links enhance operational performance? Empirical research in the auto supplier sector, International Journal of Production Economics, 2011, Vol. 133, No. 2, pp. 541-550.

[15] A. Manello and G. Calabrese, The influence of reputation on supplier selection: An empirical study of the European automotive industry, Journal of Purchasing and Supply Management, 2019, Vol. 25, No. 1, pp. 69-77.

[16] A. Petroni and B. Panciroli, Innovation as a determinant of suppliers' roles and performances: an empirical study in the food machinery industry, European Journal of Purchasing \& Supply Management, 2002, Vol. 8, No. 3, pp. 135-149.

[17] G. Premkumar, K. Ramamurthy, and S. Nilakanta, Implementation of electronic data interchange: an innovation diffusion perspective, Journal of Management Information Systems, 1994, Vol. 11, No. 2, pp. $157-186$.

[18] N. J. Pulles, J. Veldman, and H. Schiele, Identifying innovative suppliers in business networks: An empirical study, Industrial Marketing Management, 2014, Vol. 43, No. 3, pp. 409-418.

[19] F. Rodríguez, R. Muncrief, O. Delgado, and C. Baldino, Market penetration of fuel-efficiency technologies for heavy-duty vehicles in the European Union, the United States, and China, The International Council of Clean Transportation, 2017, https://theicct.org/publications/marketpenetration-fuel-efficiency-technologies-heavy-duty-vehicles-european-union, Accessed July 1, 2021.

[20] H. Saranga, R. George, J. Beine, and U. Arnold, Resource configurations, product development capability, and competitive advantage: An empirical analysis of their evolution, Journal of Business Research, 2018, Vol. 85, pp. 32-50.

[21] A. Schulze, J. Paul MacDuffie, and F.A. Täube, Introduction: knowledge generation and innovation diffusion in the global automotive industry - change and stability during turbulent times, Industrial and corporate change, 2015, Vol. 24, No. 3, pp. 603-611.

[22] C. Thomas, B. D. James, and F. D. Lomax Jr, Market penetration scenarios for fuel cell vehicles, International Journal of Hydrogen Energy, 1998, Vol. 23, No. 10, pp. 949-966.

[23] F. Wynstra, F. Von Corswant, and M. Wetzels, In chains? An empirical study of antecedents of supplier product development activity in the automotive industry, Journal of Product Innovation Management, 2010, Vol. 27, No. 5, pp. 625-639.

[24] T. Yan, S. Yang, and K. Dooley, A theory of supplier network-based innovation value, Journal of Purchasing and Supply Management, 2017, Vol. 23, No. 3, pp. 153-162. 